Artigo Original

Fisiopatologia

\title{
PERFIL EPIDEMIOLÓGICO DE CRIANÇAS E ADOLESCENTES COM INTOLERÂNCIA À LACTOSE
}

\section{EPIDEMIOLOGICAL PROFILE OF CHILDREN AND ADOLESCENTS WITH LACTOSE INTOLERANCE}

Daniela Sant'Ana de Souza ${ }^{1}$; Patrícia Machado Paraíba1; Paula Zugno 2; Cristiane Tomazi $^{3}$; Maria Cristina de Souza ${ }^{4}$; Rosilda Lopes ${ }^{5}$;

${ }^{1}$ Acadêmica de Enfermagem UNESC. danielassouza311@gmail.com.

${ }^{1}$ Acadêmica de Enferamgem UNESC. enfermagem@unesc.net

${ }^{2}$ Enfermeira*. Mestre em Oncologia. Universidade do Extremo Sul Catarinense-

UNESC.paulazugno@unesc.net

${ }^{3}$ Enfermeira. Doutora em Ciências da Saúde - UNESC. cristomazi@unesc.net

${ }^{4}$ Nutricionista. Mestre em Ciências da Saúde - UNESC.

${ }^{5}$ Enfermeira. Mestre em Ciências da Saúde - UnESC. rozilda@unesc.net

\section{Endereço para correspondência:}

* Autor correspondente: Departamento de Enfermagem, Universidade do Extremo Sul Catarinense, 88806-000 Criciúma, SC, Brazil; E-mail: paulazugno@unesc.net Tel.: +55 (48) 3431-2562. 


\section{RESUMO}

A intolerância à lactose é definida pela deficiência da lactase, denominada hipolactasia, ao qual determina a má absorção de lactose, ocorre de modo geral após os 6-7 anos de idade, apresentando um conjunto de sinais e sintomas após a ingestão de leite e laticínios. Objetivo: Identificar o perfil de crianças e adolescentes com intolerância à lactose em um ambulatório de Gastropediatria da região Sul de Santa Catarina. Método: Pesquisa de abordagem quantitativa, do tipo descritiva, exploratória, retrospectiva e documental. A coleta dos dados direcionadas à idade, sexo, cor da pele, escolaridade, região de residência, condições clínicas, aleitamento materno, sinais e sintomas, medicações utilizadas e tratamento, foi realizada por meio de prontuários das crianças e adolescentes atendidos no ambulatório de Gastropediatria, incluindo 29 prontuários durante o período de janeiro de 2013 a dezembro de 2015. A análise estatística dos dados foi realizada em planilha eletrônica pelo software Excel 2013. Resultados: A pesquisa mostrou que crianças apresentaram mais diagnósticos de intolerância à lactose do que os adolescentes. Houve predomínio da cor da pele branca. O aleitamento materno exclusivo até seis meses e o não exclusivo destacaram-se como o achado mais importante. Das crianças e adolescentes que foram alimentadas com o leite de vaca, em sua maioria o leite não era tolerado. Como principal tratamento os achados mostraram a exclusão total da lactose na dieta. Conclusão: $O$ estudo traz a importância da ingesta do leite, principalmente o materno para crianças e adolescentes que toleram um pouco do leite para que possam ingerir uma quantidade estabelecida, não precisando excluir totalmente o leite da dieta. 
Descritores: Intolerância à lactose. Crianças. Adolescentes. Perfil Epidemiológico.

\section{ABSTRACT}

Introduction: Lactose intolerance is defined by the deficiency of lactase, called hypolactasia, which determines the malabsorption of lactose, occurs generally after 6-7 years of age, presenting a set of signs and symptoms after the ingestion of milk And dairy products. Objective: To identify the profile of children and adolescents with lactose intolerance in a gastroenterology outpatient clinic in the southern region of Santa Catarina. Method: Research of quantitative, descriptive, exploratory, retrospective and documentary approach. The collection of data directed to age, sex, skin color, schooling, region of residence, clinical conditions, breastfeeding, signs and symptoms, medications used and treatment was done through medical records of children and adolescents attending the Gastropediatria outpatient clinic , Including 29 charts during the period from January 2013 to December 2015. The statistical analysis of the data was performed in spreadsheet by Excel 2013 software. Results: The research showed that children presented more diagnoses of lactose intolerance than adolescents. There was a predominance of white skin color. Exclusive breastfeeding for up to six months and non-exclusive breastfeeding stood out as the most important finding. Of the children and adolescents who were fed cow's milk, most milk was not tolerated. As a main treatment the findings showed the total exclusion of lactose in the diet. Conclusion: The study shows the importance of milk intake, especially maternal intake for children and adolescents who tolerate a little of the milk so that they can ingest an established amount, and do not need to totally exclude milk from the diet.

Descriptors: Lactose intolerance. Children. Adolescents. Profile Epidemiological. 


\section{INTRODUÇÃO}

A intolerância à lactose (IL) é um distúrbio metabólico de diagnóstico tardio. Nesses últimos anos a porcentagem de pessoas que apresentam tal patologia vem aumentando de 10 a 15\%, uma porcentagem alta para o número de pessoas, atingindo principalmente crianças ${ }^{1}$.

A IL é caracterizada como uma afecção da mucosa intestinal que resulta na deficiência da enzima lactase ( $\beta$ - D- Galactosidase) incapacitando a digestão e absorção da lactose $e^{2,3}$ e acometendo em torno de $75 \%$ da população mundial ${ }^{4}$.

A hipolactasia pode se apresentar de três diferentes formas: Congênita, primária e secundária. Em sua forma congênita, o gene é autossômico recessivo (AR), esta alteração caracteriza o quadro de diarreia grave e fezes aquosas desde a primeira ingestão do leite pelo bebê, e assim persiste durante toda a vida, exigindo a exclusão completa das fontes de lactose. A hipolactasia primária ou lactase não persistente é uma condição autossômica recessiva (AR), porém resulta no declínio fisiológico da lactase das células intestinais e apresenta em uma grande proporção de indivíduos, causando distúrbios abdominais tais como diarreia, inchaço e flatulência. Já na forma secundária, ocorre danos na mucosa do intestino, advindas de doenças como doença celíaca, de Crohn, colite ulcerosa, síndrome do intestino irritável, deficiências imonológicas, e essas podem causar uma deficiência secundária da lactase, assim como infecções bacterianas ou virais, infecções parasitárias, e requer uma dieta sem lactose até que seja restaurada a mucosa intestinal ${ }^{5}$.

Alguns autores acreditam que há milhares de anos a hipolactasia de 


\section{Artigo Original}

\section{Fisiopatologia}

origem primária acometia todas as pessoas, e que após o desmame a enzima lactase ficava inibida no organismo. Após começar a domesticação de animais que produziam leite, como bovinos, caprinos e ovinos, as pessoas começaram a consumir o leite ao longo da vida, ocasionando uma mutação genética na enzima lactase, então o organismo continuou a produzir esta enzima, o que permitia às pessoas que viviam em regiões mais frias beber leite e continuar mais saudáveis por ficarem mais nutridas ${ }^{4,6}$.

O diagnóstico de IL vem aumentando significativamente acometendo adultos e atualmente está se desenvolvendo principalmente nas crianças, sendo um motivo de preocupação para os profissionais da saúde que visam o bem-estar da população em geral. Dessa forma, torna-se essencial conhecer o processo de desenvolvimento da intolerância à lactose bem como seus principais sintomas, suas causas, a fim de obter um melhor prognóstico e consequentemente o tratamento ideal para cada indivíduo.

Nesse contexto, ressalta-se que o profissional enfermeiro muitas vezes tem o primeiro contato com a família e tem conhecimento para atender suas necessidades individuais e coletivas, pode acolher de maneira mais minuciosa estas pessoas, garantindo que tenham um acompanhamento correto, a fim de ter uma vida mais saudável e confortável.

O objetivo deste estudo foi identificar o perfil epidemiológico de crianças e adolescentes com intolerância à lactose em um ambulatório de gastropediatria da região sul de Santa Catarina.

\section{MÉTODO}


Trata-se de uma pesquisa de abordagem quantitativa do tipo descritiva, exploratória, retrospectiva documental. $O$ estudo foi desenvolvido em um ambulatório de gastropediatria da região sul de Santa Catarina. Após assinatura do Termo de Sigilo e Confidencialidade (TSC) pelos proponentes da pesquisa, foram incluídos 29 prontuários de crianças e adolescentes de zero a dezessete anos completos com IL atendidos no período de janeiro de 2013 a dezembro de 2015. Foram excluídos do estudo 143 prontuários, pois não satisfizeram o critério principal da pesquisa de ter diagnóstico de IL. A pesquisa teve aprovação do Comitê de Ética da Universidade do Extremo Sul Catarinense, sob o parecer número 1.644.477/2016.

Para a coleta de dados foi aplicado um instrumento elaborado pelas autoras no qual foram abordados os seguintes critérios: idade, sexo, cor da pele, escolaridade gênero, medidas antropométricas e hábitos alimentares, região de residência, sinais e sintomas, diagnóstico, tratamento utilizados, evolução do caso, cuidados de enfermagem, prognóstico e comorbidades, medicação prescrita/utilizada.

Para a análise quantitativa foi montado um banco de dados em planilha eletrônica. As variáveis qualitativas foram apresentadas em frequência absoluta e frequência relativa. As variáveis quantitativas foram apresentadas em mediana e amplitude interquartil (AIQ), conforme indicado.

\section{RESULTADOS E DISCUSSÕES}

De acordo com a tabela $1,51,7 \%$ das crianças e adolescentes analisadas por meio de prontuário são do sexo masculino e $48,3 \%$ do sexo feminino. Destes 


\section{Artigo Original}

\section{Fisiopatologia}

$79,3 \%$ dos pesquisados são crianças e $20,7 \%$ adolescentes. A faixa etária predominante no estudo foi de 5 a 12 anos incompletos, totalizando $58,6 \%$.

Um estudo (2004) mostrou que $44,1 \%$ da população de Joinville, SC apresentou intolerância à lactose. Sendo destes $23,71 \%$ crianças na idade 10 anos sendo $44,94 \%$ do sexo masculino ${ }^{3}$

Houve predominância da cor da pele branca $-79,3 \%$, o que difere das pesquisas literárias no mundo, as quais informam que a Intolerância à Lactose (má absorção) é muito mais frequente em negros do que em brancos ${ }^{7}$.

Com relação à escolaridade, o ensino fundamental teve maior percentual, 37,9\%. Quanto ao local de residência, a Associação de Municípios da Região Carbonífera (AMREC) comportou 86,2\%, enquanto 13,8\% foram residentes da Associação de Municípios do Extremo Sul Catarinense (AMESC).

De acordo com a tabela 2 observa-se que o teste de tolerância oral à lactose revelou um maior percentual de $31 \%$, em comparação aos demais testes, sendo que $58,6 \%$ dos prontuários não apresentaram métodos diagnósticos pela falta de registro no prontuário. No entanto os achados desta pesquisa mostram-se divergentes às pesquisas literárias. Os principais e mais utilizados testes para diagnosticar a intolerância à lactose são: o teste do hidrogênio expirado, que é considerado o padrão ouro para o diagnóstico; o teste de tolerância oral à lactose; biópsia intestinal; testes de $\mathrm{pH}$ fecal e genético ${ }^{8}$. $\mathrm{Na}$ hipolactasia primária do tipo adulto, também chamada por não persistência da lactase, pode ser determinado o diagnóstico pela biópsia intestinal (endoscopia), ou pelo teste genético pela detecção do polimorfismo específico MCM6. A intolerância secundária, pode ser diagnosticada com o teste do $\mathrm{H}_{2}$ em ar expirado, ou pelo teste de glicemia após 


\section{Artigo Original}

\section{Fisiopatologia}

carga oral de lactose. Quando o indivíduo apresenta a IL o que vai indicar é a presença sintomas como dor abdominal, diarreia e/ou meteorismo associado à má absorção da lactose ${ }^{9}$.

A pesquisa revela um percentual de $24,1 \%$ em relação as comorbidades, destes 13,8\% foi Doença do Refluxo Gastroesofágico (DRGE) e 10,3\% Déficit de crescimento.

Os parâmetros de crescimento e desenvolvimento incluem indicadores diretamente relacionados com a manutenção da saúde e nutrição infantil e, indiretamente, com a qualidade de vida da população ${ }^{10}$. Dessa maneira o papel do enfermeiro se torna ainda mais relevante no que refere à vigilância da saúde da criança, especialmente nos serviços de atenção primária à saúde.

O crescimento físico é um processo dinâmico e contínuo que ocorre desde a concepção até o final da vida, expresso pelo aumento do tamanho corporal, apresenta especificidades em cada etapa da vida e sofre influência de vários fatores, tanto genéticos como ambientais ${ }^{11}$.

Quanto ao Índice de Massa Corporal (IMC), a obtenção dos resultados foi a partir da Biblioteca Virtual em Saúde (BVS) do Ministério da Saúde (MS) que considera os valores de referência: Baixo IMC para idade (Percentil < 3); IMC Adequado ou Eutrófico ( $\geq$ Percentil 3 e $<$ Percentil 85); Sobrepeso ( $\geq$ Percentil 85 e $<$ Percentil 97) e Obesidade ( $\geq$ Percentil 97), utilizando como base para o cálculo o peso, altura, sexo e a idade em anos, meses, semanas e dias. De acordo com os cálculos obteve-se os seguintes resultados: 48,3\% estavam eutróficos, $27,6 \%$ apresentaram sobrepeso, 13,8\% Baixo Peso, 6,9\% obesidade, e outros 6,9\% não apresentaram registro de peso e altura no prontuário. Segundo Téo, 2002, Existem 


\section{Artigo Original}

\section{Fisiopatologia}

casos de acometimento da desnutrição devido à má absorção intestinal, dependendo da intensidade e constância do caso clínico, devido a alterações na taxa de esvaziamento gástrico ${ }^{12}$.

De acordo com a tabela 3, que aborda os hábitos alimentares e sinais e sintomas, percebe-se que $20,7 \%$ das crianças e adolescentes receberam aleitamento materno exclusivo até seis meses de idade, 10,3\% receberam aleitamento materno não exclusivo, porém em sua maioria, 69\% não se pôde avaliar a questão do aleitamento materno, pois não tiveram algum tipo de registro no prontuário.

Um dos fatores para o desenvolvimento de intolerância a lactose é o leite de vaca ser introduzido na alimentação de crianças antes dos 03 meses de vida, pois o leite de vaca é metabolizado diferentemente do leite materno o que torna mais difícil a absorção ${ }^{13}$.

Neste sentido, o enfermeiro tem importante papel no cuidado com as crianças e adolescentes, principalmente na atenção básica, ao qual tem contato com as mães desde gestantes no pré-natal, parto e puerpério, e podem informar e aconselhar sobre a prática do aleitamento materno exclusivo até os seis meses de idade.

No que refere a ingesta do leite, o estudo mostra que $72,4 \%$ das crianças e adolescentes que foram alimentados com leite de vaca não toleram o mesmo, 13,8\% toleram pouco e 13,8\% não havia registro sobre a tolerância ao leite de vaca.

A quantidade de lactose ingerida para causar os sintomas varia de indivíduo para indivíduo e depende de alguns fatores como, a quantidade ingerida de lactose, em qual forma alimentar ela foi ingerida, e qual o grau de deficiência de 


\section{Artigo Original}

\section{Fisiopatologia}

lactase. Em uma criança por exemplo, a ingestão de $12 \mathrm{~g}$ de lactose pode ser suficiente para causar dor abdominal crônica ${ }^{14}$.

Os sinais e sintomas predominantes nas crianças e adolescentes com IL foram a distensão e dor abdominal com $65,5 \%$, seguido da diarreia com $44,8 \%$, episódios de êmese $24,1 \%$, náusea e constipação 24,1\%, fezes amolecidas 13,8\%, e as fezes com muco e/ ou sangue, fezes endurecidas e cefaleia permaneceram respectivamente com $6,9 \%$ dos sinais e sintomas apresentados.

Os sintomas apresentados por pacientes intolerantes à lactose podem ser gastrintestinais ou sistêmicos. Os sintomas gastrintestinais envolvem dor abdominal, distensão abdominal, borborigmo e flatulência em uma frequência de 100\%, diarreia $70 \%$, constipação 30\%, náusea e vômito 78\%. Os sintomas sistêmicos envolvem dor de cabeça e tontura em uma frequência de $86 \%$, perda da concentração e pobre memória de curto prazo $82 \%$, cansaço severo prolongado $63 \%$, dor muscular e dor nas articulações $71 \%{ }^{15,16}$.

$\mathrm{Na}$ apresentação dos resultados referente a tabela 4, abordou-se 0 tratamento medicamentoso e o prognóstico, revelando que $86,2 \%$ das crianças e adolescentes faziam uso de algum medicamento, dentre os quais tomou destaque o uso do polietilenoglicol com $24,1 \%$, enzimas digestivas $24,1 \%$, omeprazol $17,2 \%$ domperidona $6,9 \%$ e ainda aqueles que faziam uso de outras medicações $62,1 \%$, independente ao tratamento.

“O tratamento da IL não deve objetivar reduzir a má absorção mas melhorar os sintomas dispépticos"17.

Preparados comerciais de "lactase", quando adicionados a alimentos que contenham lactose ou ingeridos com refeições com lactose, são capazes de reduzir 
os sintomas e os valores de hidrogênio expirado em muitos indivíduos intolerantes à lactose. Entretanto, cada paciente pode reagir de alguma forma pois não é hidrolisada completamente a lactose da dieta ${ }^{18}$.

Quanto ao prognóstico das crianças e adolescentes, foram definidos conforme a sintomatologia apresentada pelos pacientes, após orientações e tratamento prévio no ambulatório de gastropediatria, os resultados obtidos foram os seguintes: melhora dos sintomas $79,3 \%$, mantiveram estável $3,4 \%$, e $17,2 \%$ estavam sem registro, não se constatou nenhum caso de agravo dos sintomas.

Nos casos de Deficiência Secundária, o prognóstico é muito bom e ao tratar a doença que deu origem à lesão, desaparecem os sintomas da intolerância e o paciente poderá voltar a ingerir alimentos que contenham lactose ${ }^{19}$.

Como principal tratamento nota-se que os resultados da tabela 5 foram: $48,3 \%$ das crianças e adolescentes resultaram na exclusão total da lactose, exclusão parcial da lactose $34,5 \%$, uso de enzimas digestivas $10,3 \%$ e sem registro $6,9 \%$. A remoção da lactose em indivíduos com elevado apetite por leite é muito difícil, o que torna a resposta clínica por vezes incompleta ou inconsistente. A relação dos sintomas e dieta em pacientes com DTF, pode causar a supressão desnecessária de leite em alta proporção da população, o que alerta sobre o risco de ingestão inadequada de cálcio e vitamina $D$ nesses pacientes, o que sugere a possibilidade de confirmar IL, com utilização dos métodos diagnósticos em casos em que a resposta clínica não está muito clara ${ }^{9}$.

O tratamento basicamente consiste na retirada ou redução do consumo do leite e seus derivados, e que o intolerante deve estar ciente que além do leite in natura, existem outros alimentos que contém lactose, além de derivados do leite ${ }^{20}$. 
Sobre a evolução dos casos $65,5 \%$ continuaram em acompanhamento no ambulatório de Gastropediatria, os demais permaneceram em tratamento $34,5 \%$. A regulação da assistência à saúde tem a função primordial de ordenar o acesso às ações e aos serviços de saúde, em especial à alocação prioritária de consultas médicas e procedimentos diagnósticos e terapêuticos aos pacientes com maior risco, necessidade e/ou indicação clínica oriundos dos diversos serviços de saúde em tempo oportuno 20 .

Os achados revelam que $10,3 \%$ dos pacientes que continuaram em tratamento, faziam uso contínuo de enzimas digestivas e outras medicações, como polietilenoglicol, e precisavam manter o tratamento para possíveis reajustes de doses ou troca de alguma medicação. Os pacientes que estavam em acompanhamento precisavam continuar suas consultas, a fim de o profissional avaliar a adesão da dieta, assim como sua eficácia.

\section{CONCLUSÃO}

As crianças (5 - 12 anos) foram que mais tiveram diagnóstico de intolerância à lactose, algumas apresentaram déficit do crescimento, uma comorbidade preocupante, que pode ter relação com os sinais e sintomas que mais prevaleceram que foram a diarreia, distensão, dor abdominal e fezes amolecidas, no que diz respeito a amamentação exclusiva ou não, não houve relatos de maior parte das crianças e adolescentes, o que faz refletir sobre a importância do leite materno, que traz inúmeros benefícios nutricionais e também protege as crianças contra doenças. O estudo traz a importância para crianças e adolescentes que ainda toleram um pouco do leite que possam ingerir uma quantidade estabelecidas, sendo 


\section{Artigo Original}

\section{Fisiopatologia}

que algumas faziam uso da enzima digestiva, não precisando excluir totalmente o leite da dieta.

$$
\text { É de grande importância a contribuição desta pesquisa para os }
$$
profissionais da saúde, considerando admirável a atuação do enfermeiro na prática do cuidado com crianças e adolescentes, garantindo assistência no que refere ao crescimento e desenvolvimento saudável, em conjunto interdisciplinar, e ao fato de que crianças precisam do leite devido suas composições nutricionais ricas,

principalmente para crianças que toleram pouco é muito importante ingerir uma quantidade estabelecida. Mas também orientar sobre outras fontes alimentícias de cálcio.

\section{REFERÊNCIAS}

1. Porto C.P.C, Thofehrn M.B, Sousa A.S.de, Cecagno D. Experiência vivenciada por mães de crianças com intolerância à lactose. fam. saúde desenv., curtiba, set/dez 2005; 7(3): 250-256.

2. Casagrande, M.; Pistorello, RI.; Bisi, B. Intolerância à lactose. Periódicos IFRS, Caxias do Sul, set. 2014; (3).

3. Frye, RE. Lactose intolerance. Clínica Fellow, Departamento de Neurologia, Hospital de Crianças de Boston, Escola Médica Harvard, 2002.

4. Pereira Filho D.; Furlan, S.A. Prevalência de intolerância à lactose em função da faixa etária e do sexo: experiência do laboratório Dona Francisca, Joinville. Revista Saúde e Ambiente, Junho 2004, 5(1).

5. Palacios, R; Herkenhoff, ME. O gene da intolerância à lactose. Genética na Escola, [s.I.], 2014; 9(2). 
6. Mattar, R. Mazo, DFC. Intolerância à lactose: mudança de paradigmas com a biologia molecular. Rev. Assoc. Med. Bras, São Paulo, SP. 2010; 56(2) p. 230-236.

7. Barbosa, CR.; Andreazzi, MA. Intolerância à lactose e suas consequência no metabolismo do cálcio. Revista Saúde e Pesquisa. 2011 jan./abr. 4(1): p. 81-86.

8. Pinto, LPS. et al. Uso de probióticos para o tratamento do quadro de Intolerância à Lactose. Revista Ciencia \& Inovação, [s.I.], v.2, n.1, dez. 2015.

9. Rollán Antonio, Vial Cecilia, Quesada Soledad, Espinoza Karena, Hatton Mary, Puga Alonso et al . Diagnóstico de intolerancia a la lactosa en adultos: rendimiento comparativo de la clínica, test de hidrógeno espirado y test genético. Rev. méd. Chile [Internet]. 2012 Set [citado 2016 Dez 07] ; 140( 9 ): 1101-1108.

10. Reichert, APS, Almeida AB, Souza LC, Silva MEA, Collet N. Vigilância do crescimento infantil: conhecimento e práticas de enfermeiros da atenção primária à saúde. Rev Rene. 2012; 13(1):p.114-26.

11. Spyrides, MHC. et al. Efeito das práticas alimentares sobre o crescimento infantil. Rev. Bras. Saúde Materna. 2005; 5(2) p. 145-153.

12. Téo, CRPA. Intolerância à lactose: uma breve revisão para o cuidado nutricional. Arquivos de Ciências da Saúde da Unipar, Toledo, 2002; 3(6): p.135-140.

13. Santos, KWP, Zanusso Júnior, G. Análise da Prevalência de Portadores de Intolerância à Lactose por Exames Laboratoriais em Maringá-PR. Revista Uningá, [s.l.], jul/set 2015; 45, p.11-15.

14. Heyman, MB. Lactose intolerance in infants, children nd adolescents. Pediatrics, Set, 2006; 118:(3). 
Artigo Original

Fisiopatologia

15. Matthews, SB, Waud, JP, Roberts, AG, Campbell, AK. Systemic lactose

intolerance: a new perspective on an old problem. Postgrad Med J 2005; 81: 167173.

16. Friedrich DC. A diversidade do gene LCT e a persistência da lactase na população brasileira. 106f. Tese submetida ao programa de pós-graduação em genética e biologia molecular. 2013. Universidade Federal do Rio Grande do Sul Porto Alegre.

17. Fernandes, Carlos Eduardo Ramos. Intolerância à lactose. Trabalho de conclusão de curso. 2014, São Paulo.

19. Antunes, AEC, Pacheco, MTB. Leite para adultos: mitos e fatos frente à ciência. 1. ed. 2009, São Paulo: Varela.

20. Fernandes, TF. Intolerância à Lactose. Revista Brasileira de Medicina, [s.I.], jun. $2015 ; 72(6): 267-270$.

21. Brasil. Ministério da Saúde. Endocrinologia e nefrologia / Ministério da Saúde, Universidade Federal do Rio Grande do Sul - Brasília -DF: 2015; 1 p.20.

TABELAS

Tabela 1 - Perfil das Crianças e Adolescentes

\begin{tabular}{lll}
\hline Características & $\mathbf{N}$ & $\%$ \\
\hline Crianças & 23 & 79,3 \\
Adolescentes & 6 & 20,7 \\
Idade (Mediana, Média, Mínimo-Máximo) & & $9,6 \quad 8,6 \quad 0,5-17,5$ \\
Sexo & 15 & 51,7 \\
Masculino & 15
\end{tabular}

Revista Inova Saúde, Criciúma, vol. 7, n. 1, jul. 2018.

ISSN 2317-2460 
Artigo Original

Fisiopatologia

Feminino

Cor da pele

Branca

23

79,3

Negra

1

3,4

Sem registro

5

17,2

Escolaridade

Educação infantil

6

20,7

Ensino fundamental

11

37,9

Ensino médio

3

9

10,3

Sem registro

31,0

Região de residência

AMREC

25

86,2

AMESC

4

13,8

Fonte: dados da pesquisa (2016). AMREC: Associação de Municípios da Região

Carbonífera; AMESC: Associação de Municípios do Extremo Sul Catarinense

Tabela 2 - Condições Clínicas

\begin{tabular}{lll}
\hline Método Diagnóstico & $\mathbf{N}$ & $\%$ \\
\hline Teste oral de tolerância à lactose & 9 & 31,0 \\
Detecção genética & 1 & 3,4 \\
H2 expirado & 2 & 6,9 \\
Sem registro & 17 & 58,6 \\
Comorbidades & & \\
Sim $\quad 7$ & 24,1 \\
$\quad$ DRGE & 4 & 13,8 \\
$\quad$ Déficit do Crescimento & 3 & 10,3 \\
Não & 22 & 75,9 \\
IMC & & \\
Baixo peso & 4 & 13,8 \\
Peso adequado & 14 & 48,3 \\
Sobrepeso & 8 & 27,6 \\
Obesidade & 2 & 6,9 \\
Sem registro & 2 & 6,9 \\
\hline
\end{tabular}

Fonte: dados da pesquisa (2016). H2: Fórmula molecular do gás hidrogênio; DRGE: Doença do Refluxo Gatroesofágico; IMC: Índice de Massa Corporal

Tabela 3 - Aleitamento Materno e Sinais e Sintomas

\begin{tabular}{lll}
\hline Aleitamento Materno & N & Percentual \\
\hline Aleitamento Materno exclusivo & 6 & 20,7 \\
Aleitamento Materno & 3 & 10,3 \\
Sem registro & 20 & 69,0
\end{tabular}

Revista Inova Saúde, Criciúma, vol. 7, n. 1, jul. 2018.

ISSN 2317-2460 
Artigo Original

Fisiopatologia

Tolerância ao leite de vaca

Não tolera

Tolera Pouco

72,4

Sem registro

Sinais e Sintomas

4

13,8

Náusea

4

17,2

Êmese

5

24,1

Diarreia

7

44,8

Distensão e dor Abdominal

Constipação

Fezes com muco elou sangue

20,7

Fezes amolecidas

6

6,9

2

Fezes endurecidas

4

13,8

Cefaleia

2

6,9

2

6,9

Fonte: dados da pesquisa (2016).

Tabela 4 - Medicações utilizadas

\begin{tabular}{lll}
\hline Uso de medicações & $\mathbf{N}$ & $\%$ \\
\hline Propiletilenoglicol & 7 & 24,1 \\
Enzimas digestivas & 7 & 24,1 \\
Domperidona & 2 & 6,9 \\
Omeprazol & 5 & 17,2 \\
Outras Medicações & 18 & 62,1 \\
Prognóstico & & 79,3 \\
Melhora dos sintomas & 23 & 0,0 \\
Agravo dos sintomas & 0 & 3,4 \\
Manteve Estável & 1 & 17,2 \\
Sem registro & 5 &
\end{tabular}

Fonte: dados da pesquisa (2016).

Tabela 5 - Tratamento

\begin{tabular}{lll}
\hline Principal tratamento & $\mathbf{N}$ & $\%$ \\
\hline Exclusão parcial da lactose & 10 & 34,5 \\
Exclusão total da lactose & 14 & 48,3 \\
Enzimas digestivas & 3 & 10,3 \\
Sem registro & 2 & 6,9 \\
Evolução & & \\
Em tratamento & 10 & 34,5 \\
Encaminhado para outro Serviço & 0 & 0,0 \\
Em acompanhamento & 19 & 65,5 \\
\hline
\end{tabular}

Fonte: dados da pesquisa (2016). 